\title{
EL DEBATE SOBRE LA PROVISIÓN PLURALISTA DE LOS SERVICIOS SOCIALES
}

\author{
TRINIDAD BANDA GALLEGO
}

Profesora titular de la Escuela Universitaria de Trabajo Social. Universidad de Huelva.

\section{RESUMEN}

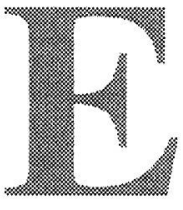

1 artículo que me propongo desarrollar versa sobre un tema de gran actualidad, la provisión pluralista de Servicios Sociales, planteado en tono de debate, porque en lo que se vislumbra respecto a este tema lo que existe son tendencias, pero aún no hay nada decidido sobre el giro que tomará la provisión de servicios. Se tratan aspectos sustanciales que dan cuerpo al debate, tales como las propuestas ideológicas que lo determinan, la relación entre Estado y sociedad civil, la diferencia entre los sectores que ya, de hecho, están presentes, para ver, por último, las ventajas y los límites que tienen cada uno de ellos. Es un debate fructífero al que habremos de contribuir todos los que, de alguna manera, estamos relacionados con la provisión de servicios de bienestar y, quizás, llegar al planteamiento de la necesaria complementariedad entre cada uno de los sectores implicados, porque ninguno de ellos reúne, en sí mismo, los requisitos necesarios para ofrecer una efectiva provisión de los servicios necesarios.

\section{PALABRAS CLAVE}

Pluralismo del bienestar, sociedad civil, Estado, iniciativa social, complementariedad, equidad, voluntariado, mercado.

\section{INTRODUCCIÓN}

La provisión pluralista de Servicios Sociales puede ser utilizada para expresar el hecho de que la atención social que un individuo recibe puede ser obtenida, y de hecho se obtiene, a través de cuatro sectores diferentes: 
- el sector público,

- el sector privado no lucrativo (voluntario),

- el sector privado lucrativo (comercial),

- y el sector informal.

No obstante, este tema hay que inscribirlo en el debate más amplio del «pluralismo del bienestar» que es un debate relativamente reciente, y es un debate anglosajón, iniciado y mantenido en países como Gran Bretaña y Estados Unidos. En España también se habla de él, por parte de autores como Rodríguez Cabrero' y García Roca, aunque éste último le denomina sistema mixto. Los pluralistas parten de unas situaciones básicas y es que el «bienestar» deriva de las cuatro fuentes que hemos nombrado con anterioridad, por tanto, el bienestar social, como responsabilidad de todos, debe ser la suma de esos cuatro sectores, dando lugar a una gran variedad de modos de provisión de recursos. El pluralismo del bienestar trata de transferir responsabilidades, principalmente de producción y gestión de servicios, desde el Estado a los otros sectores, manteniendo el primero funciones muy concretas. Entre todos ellos existen diferencias importantes en cuanto a la razón fundamental que justifica la distribución de recursos; se pueden señalar entre otros, la equidad, la lealtad familiar, el altruismo, la capacidad de pagar, etc.

La frontera entre los dominios público y privado es polémica, cambiante y se halla mal definida. Cada cultura, guiada por los valores de los que ella misma se dota, construye sus propias estructuras institucionales para crear y distribuir riqueza y bienestar. Esta estructura institucional se ve muy influenciada por la tradición, la ideología y la inercia, aunque a veces también entren en el proceso, el análisis y un deseo intencional. En las sociedades capitalistas pueden distinguirse tres principios organizativos para la producción y el intercambio ${ }^{2}$.

El Gobierno, donde son las decisiones políticas, respaldadas por la autoridad, más que por la benevolencia o los precios, las que determinan qué se produce y cómo se distribuye. En una cultura democrática, el gobierno es un mecanismo de coordinación, un dispositivo para detectar necesidades y asignar recursos. Nos comprometemos a pagar mutuamente por lo que todos nosotros necesitamos.

El sistema de precios, donde el principio organizativo es el intercambio recíproco, en interés propio y en cuya interdependencia me-

RODRIGUEZ CABRERO, G., «Entre la protección social y el bienestar social» en Varios Autores: Reflexiones sobre política esconómica, Popular, Madrid, 1990, pp.228-229.

2 DONAHUE, J.D., La decisión de privatizar. Fines públicos, medios privados, Paidós, Barcelona, 1991, pp.31-35. 
dia un precio -el mercado- que opera en todas las culturas. Dame lo que yo quiero y te daré lo que tú quieres.

El voluntarismo, por el que la gente actúa en interés de otros, sin compensación y sin coerción, impulsada ya sea por la tradición, ya sea por un sentido del deber familiar, social o religioso, por simple empatía o por la emoción que brinda el poder implícito de la propia generosidad. El voluntarismo no espera reciprocidad en la transacción. Por lo que te doy no espero nada a cambio.

El debate amplio sobre el pluralismo del bienestar o sistema mixto surge en el contexto de la crítica al Estado de Bienestar y los problemas planteados por la crisis del mismo, aunque otros prefieren llamarlo crisis en el Estado de Bienestar, que comienza a partir de los años 70 , en que comienza a haber un recorte de los gastos sociales, y es a partir de ese momento cuando comienza a surgir una corriente de pensamiento que propugna la necesidad de que todos los sectores mencionados con anterioridad participen en la producción y gestión del bienestar, que si bien han existido siempre, ahora se trata de hacer su presencia más efectiva, ya que esperar que la administración pública suministre todos los servicios necesarios es una utopía. Más concretamente, el pluralismo del bienestar implica que el estado juegue un papel menos dominante, no viendo a éste como el único instrumento posible para dar una provisión colectiva de servicios sociales y mantener y maximizar el bienestar.

Son numerosas las críticas feroces que se alzaron contra el mismo, porque con su intervención no había conseguido incrementar la solidaridad y la igualdad como se había esperado.

Algunas de esas críticas tienen el siguiente tono:

Watzlawick, en su libro El arte de amargarse la vida, dice «como los directores de un zoológico en dimensiones reducidas, en grandes dimensiones los Estados se han propuesto la tarea de configurar la vida de los ciudadanos de manera que ésta, desde la cuna a la tumba, sea segura y chorreante de felicidad. Pero esto es sólo posible mediante una educación sistemática del ciudadano que le haga incompetente en la sociedad $»^{3}$.

Reacciones como ésta, que se han concentrado sobre los fallos de la provisión estatal, son las que intentan devolver el protagonismo y la responsabilidad a la población, intentando impulsar organizaciones sociales, grupos de ayuda mutua, y recuperar las redes naturales, familiares y comunitarias como principal vía de apoyo, ayuda y asistencia. Pero un sistema pluralista conlleva también un papel para el sec- 
tor comercial (mercado privado), aunque los pluralistas más moderados, aún cuando acepten la provisión mercantil, se muestran más entusiastas con la provisión por parte de organizaciones voluntarias. Estas críticas están insertas en la tesis de que con el Estado de Bienestar los individuos lo esperan todo de los estados y poco de la sociedad en la que viven. Se potencia el individualismo (pasividad), se reduce la sensibilidad ante las desigualdades, se pierde el sentido cívico, y se hacen reivindicaciones categoriales, más que el mantenimiento de una actitud estrictamente reivindicativa.

Hay otro motivo por el que se propugna un sistema de provisión pluralista y es por el fundamento antropológico y moral del mismo, en cuanto a diferenciar entre el concepto de necesidad que se contrapone a aspiraciones ${ }^{4}$, deseos y preferencias ${ }^{5}$. Las necesidades son básicas, fundamentales e inmutables; no pueden ser elegidas y no pueden eludirse. Las preferencias, aspiraciones y deseos son secundarias, instrumentales, son demandas subjetivas que responden a imperativos funcionales. Una vez satisfechas las necesidades por parte del Estado, la sociedad es libre para facilitar la satisfacción de estas últimas.

Aunque hacer la distinción entre ambas no es tarea fácil, ya que están sometidas a criterios de valoración, que son necesariamente subjetivos; por ello, al no ser las necesidades, ni objetivas ni neutras, ni inequívocas, no pueden ser la instancia principal para la definición el bienestar, pero, a juicio de Harris, es su componente esencial ${ }^{6}$.

Dos temas estrechamente ligados con el Pluralismo del bienestar son la descentralización y la participación. El término descentralización significa el desplazamiento de las responsabilidades del gobierno central al regional y de este al local, porque la filosofía del pluralismo está en que es cada localidad la que ha de estudiar el equilibrio concreto de servicios que se adecúe mejor a sus necesidades, y estarían más al tanto de las ayudas voluntarias e informal. La descentralización está vinculada con la participación, de la que Rodríguez dice que es un instrumento del principio de solidaridad y se fundamenta en que la persona, a través de la actividad responsable de la participación se perfecciona a sí misma, asumiendo las consecuencias de sus actos. En la medida en que el marco social es manipulable por el hombre, ya que no le viene impuesto con el rigor del medio físico y natural, la persona puede influir sobre él, bien sea por la vía de la simple

4 DOYAL, L y GOUGH, I., Teoría de las necesidades humanas, Icaria, Barcelona, 1994, pp.6768.

5 HARRIS, D., Justificación del Estado del Bienestar, Instituto de Estudios Fiscales, Madrid, 1987, pp.303 y ss.

6 HARRIS, D., op.cit. pp. 316. 
intervención positiva, o bien modificando las instituciones concretas. Los ámbitos donde ha de darse la participación no sólo han de existir, sino que han de llevar una vida activa y no ser aprisionados por la acción indiscriminada de entes sociales superiores?

\subsection{Propuestas determinantes en el debate}

Para García Roca, la construcción del pluralismo del bienestar o sistema mixto se diseña sobre tres propuestas que se muestran insuficientes y determinan el actual debate ${ }^{8}$ :

La Conservadora: que focaliza la política social sobre los grupos primarios (la familia, el voluntariado, las organizaciones solidarias), ya que la intromisión del Estado daña y erosiona la fortaleza de las otras instituciones. Proponen una reducción de los gastos sociales, disminuyendo las demandas hacia el sector público. Esta postura sugiere que la iniciativa social pueda desempeñar las funciones del sector público en el ámbito del bienestar social con una mayor eficacia. Aunque a esta postura se le puede hacer una objeción y es que el Estado de Bienestar surge, precisamente, y entre otros motivos, porque ni el sector mercantil ni el sector no lucrativo satisfacían adecuadamente las necesidades sociales sentidas por los ciudadanos.

La Liberal: que se opone por principio a cualquier regulación de la actividad económica por parte del Estado. Se interesan básicamente por el mercado, en el que descubren la panacea de la creación de riqueza y de protección social, siendo el puro mecanismo del mercado el que resolverá todos los problemas.

La Estatista: que focaliza la atención social sobre la exclusiva responsabilidad del Estado que se reviste de magia y se sitúa por encima de todas las instancias sociales, potenciándose las estructuras normativas que se organizan en burocracias e instituciones estatales. Se oponen a cualquier iniciativa que suponga una promoción del papel de la iniciativa social o el mercado; el argumento es que ello supondría una intromisión en el campo de la competencia del sector público, cuyos efectos más generales entrarían en conflicto con una política de bienestar eficaz y equitativa. La objeción a esta postura es que ello supondría una forma de «totalitarismo social», contrario a los principios democráticos y al pluralismo social.

Pero estas posturas no son tan radicales como García Roca expone, pienso que se van aproximando y emerge la cuestión de la relación

7 RODRÍGUEZ, F., Introducción a la política social, Fundación Universidad Empresa/Cívitas, Madrid, 1979, pp. 381-383.

* GARCÍA ROCA, J., Público y privado en la acción social. Del Estado de Bienestar al Estado Social, Popular, Madrid, 1992, pp. 62-63. 
entre lo gubernamental y lo no gubernamental o entre lo público y lo privado. La separación comienza a romperse cuando las instituciones públicas deciden recurrir a las instituciones no gubernamentales para ofrecer un servicio determinado a través de la contratación externa, de la que hablaremos posteriormente. También se rompería cuando los poderes públicos deciden reforzar la capacidad de transferencia de recursos de las otras instituciones, actuando sobre el lado de la demanda, en la que los ciudadanos, a través de una reducción de los impuestos comprarían u organizarían su propio bienestar. El Estado sólo apoyaría, con una transferencia en dinero, a aquéllos que no pudieran manejarse con esas instituciones. O bien habría un tercer tipo de relación, por la que el Estado ofrecería un mínimo universal, y más allá del mismo, las instituciones no gubernamentales serían las encargadas de responder a las expectativas de cada uno.

El pluralismo del bienestar ocupa un lugar central en este momento, ya que hay argumentos para toda clase de matices. Tiene una ventaja y es estar basado en un sistema que ya es mixto; se trataría de combinarlos en distintas proporciones; «los ingredientes serían los mismos, pero la receta sería diferente» (Aliena Miralles, 1992). La corriente conservadora puede verlo como:

- Una fórmula políticamente conveniente para hacer frente a la sobrecarga del gobierno y la crisis fiscal, al reducir el papel del Estado.

- También puede ser visto como una oportunidad de transferir los servicios públicos hacia el mercado privado, introduciendo así lo que piensan que es un saludable elemento de competencia y elección, lo que fomenta un espíritu de confianza y de independencia.

- Otro factor que se señala puede ser la regeneración de la asistencia familiar, suponiendo que haya habido una degeneración de la misma. En este sentido, Friedman dice "Creemos que uno de los costos mayores del actual sistema de bienestar es que no sólo mina y destruye la familia, sino que también envenena los impulsos de las actividades asistenciales privadas»".

La corriente progresista también verá gustosa las implicaciones antiburocráticas, anticentralistas y antiprofesionales del pluralismo, sin embargo, rechazan la provisión por el mercado y la provisión por las amplias y tradicionales organizaciones voluntarias. Desde esta corriente se reclama el pluralismo del bienestar desde un sentido democrático cuyas ventajas residirían en un estilo más participativo en la provisión de los servicios que respondería de forma más rápida y sensible a las necesidades de la gente. 
Mishra piensa que, por el momento, es la primera de las corrientes la que se está imponiendo, lo que significai" más mercado, más privatización, mayor libertad económica y mayor desigualdad.

Estos son los que forman parte de lo que Galbraith llama la «mayoría satisfecha», de la que da cuatro características ${ }^{11}$ :

1. Están convencidos de que lo que reciben es lo que merecen en justicia, ya que es el producto de su esfuerzo, su inteligencia y su virtud personales. La equidad no debe justificar ninguna acción que reduzca lo que disfrutan o podría disfrutarse. La reacción habitual es la indignación contra lo que usurpa aquello que tan claramente se merece.

2. La segunda característica es su actitud hacia el tiempo; prefieren siempre que el gobierno no actúe, aún a riesgo de que las consecuencias puedan ser alarmantes a largo plazo; puesto que éste puede no llegar y el costo de la actuación del presente recaería (con una subida de impuestos) sobre esa mayoría satisfecha. Los costos actuales son específicos, y el beneficio futuro difuso. Prefieren el beneficio a corto plazo.

3. El Estado es visto como una carga, porque consideran que es inadmisible que se intervenga en algo que está previsto que salga bien; el compromiso con el «laissez faire» es una actitud, es el convencimiento de que, por la propia naturaleza de las cosas, al final todo funciona bien $(1992,69)$. Galbraith lo expresa como «quitar al Estado de las espaldas de la gente», aunque a esta condena hay significativas excepciones. Lo que se considera una carga para el Estado son todas aquellas medidas que benefician precisamente a los intereses de los grupos no privilegiados: gasto en servicios sociales, en viviendas de protección oficial, instalaciones de infraestructura, deportivas, culturales y recreativas en los barrios más pobres, etc.

4. La última característica es la tolerancia que muestran los satisfechos respecto a las grandes diferencias de ingresos: prevenirse contra cualquier ataque a la propia renta es tolerar una mayor cuantía para otros. La opulencia esplendorosa de los muy ricos es el precio que paga la mayoría electoral satisfecha para poder retener lo que es menos, pero que de todos modos está muy bien. Lo expresa del siguiente modo: «Para ayudar a la clase media y a los pobres se deben reducir los impuestos de los ricos» que se corresponde con la teoría vulgar, de que si se alimenta al caballo generosamente

10 MISHRA, R., «El Estado de Bienestar después de la crisis: Ios años 80 y más allá» en Varios Autores: Crisis y fituro del Estado de Bienestar, Alianza, Madrid, 1993, pp. 121.

"GALBRAITH, J.K., La cultura de la satisfaccioin, Ariel, Barcelona, 1992, pp.32-34. 
con avena, algunos granos caerán en el camino para los gorriones» ${ }^{12}$.

\section{RELACIÓN ESTADO-SOCIEDAD CIVIL}

Pero en este debate lo que se está planteando realmente es la relación existente entre el Estado y la sociedad civil o el retorno de esta última, que significa un replanteamiento de las relaciones entre ambas, reinyectando en el cuerpo social las responsabilidades que se han hecho recaer sobre el Estado.

Para ver esta relación, yo me he servido de un libro de Víctor Pérez Díaz, que lleva por título, precisamente, «El retorno de la sociedad civil» ${ }^{13}$ donde, a través de una metáfora, el flujo y reflujo de las mareas, el flujo alternado de avances y retrocesos del mar y de la tierra establece dicha relación. Hegel pensaba que el mar es la infinitud y la inquietud: siempre, aún cuando calmo, en estado de agitación y zozobra. El mar es, por excelencia, el escenario para la acción de las gentes de costas, de sociedades dedicadas a tareas de descubrimiento y explotación del mundo, dedicadas al comercio, la ciencia, la exploración y la piratería. Parece el símbolo propio de una sociedad civil impulsada por las pasiones y los intereses de miles de individuos y grupos pequeños, siempre renovados y cambiantes. Sobre la tierra compacta, en cambio, se proyectan típicamente los sueños de dominación y estabilidad de hombres de estado, funcionarios y militares; en ella, se fijan y se guardan las fronteras de un territorio de dominación; se construyen los grandes edificios y monumentos que son símbolos y expresión de una voluntad de estabilidad y permanencia. «Flujo y reflujo», metáfora que nos sirve para ver una semejanza entre la relación cambiante de tierra y mar y de Estado y sociedad civil.

A su juicio, sociedad civil y Estado, aunque etimológicamente sean términos próximos, se han llegado a convertir en términos que denotan realidades muy distintas, piensa que la gente cada vez más entiende la sociedad civil como en oposición al concepto de Estado, y se usa en el contexto de debates centrados en el problema de cómo definir las fronteras apropiadas y las relaciones adecuadas entre ambos. $\mathrm{La}$ sociedad es civil en tanto que sus agentes son ciudadanos y no meros súbditos de un déspota o una casta dominante, $y$, por tanto, miembros de una sociedad civilizada, y no de una sociedad bárbara o atrasada.

GALBRAITH, J.K., op.cit. pp.39.

PÉREZ DÍAZ, V., El retorno de la sociedad civil, Instituto de Estudios Económicos, MAdrid, 1987, pp.14-16. y PÉREZ DÍAZ, V., La primacía de la sociedad civil, Alianza Editorial, Madrid, 1994, pp.86. 
Cobo Suero, da un concepto de sociedad civil que desde mi punto de vista engloba bastante bien lo que actualmente es o quiere ser: «un conjunto heterogéneo de individuos, grupos organizados, movimientos sociales e instituciones de carácter económico, social, cultural y religioso no mediados o apenas mediados por partidos o instituciones políticas, que aportan su creatividad y trabajo para responder a los retos que ha de afrontar la sociedad» ${ }^{14}$.

En este debate no se trata de enfrentar al Estado con la sociedad civil sino que se redefina su relación complementaria y suplementaria. No se trata de menos estado y más sociedad civil, pues, como dice Rodríguez Cabrero, si el monopolio estatal de la producción del bienestar se convierte en burocratización, cabe pensar que el predominio de la sociedad civil en sociedades industriales llegue a ser una sociedad incivil donde los grupos sociales menos organizados y hábiles quedarán en los márgenes o extrarradios de la sociedad.

Y esta relación complementaria pienso que ya se está dando, desde el momento en que el Estado acuda cada vez más a la contratación externa de servicios que significa hacer con medios privados actividades que son fines públicos y abarca diversas realidades:

1 La contratación específica propiamente dicha: tras una convocatoria pública, el poder público contrata con una entidad privada la producción de un determinado servicio.

2. El reembolso, que consiste en pagar un precio previamente acordado por unidad de servicio.

3. Contratar con agencias delegadas, que asumen la responsabilidad total en la satisfacción de las necesidades de un grupo de clientes específicos a cambio de un pago que cubra todos o parte de los servicios de los costos del contratista.

4. Ayudas públicas a entidades voluntarias o privadas para que provean servicios que complementen o sustituyan la provisión estatal.

Esta modalidad de contratación externa de servicios (que es una privatización) trae dos consecuencias importantes:

1. La reestructuración del papel del estado que ha de aumentar su capacidad reguladora. Se entiende que un gran número de servicios propios constituye un estorbo para la verdadera función de un gobierno, que es tomar decisiones políticas. Un gobierno debe proveer servicios, no necesariamente producirlos. Menos producción gubernamental, significa más tiempo para evaluar qué servicios deben ser provistos, dónde y cómo.

14 COBO SUERO, J.M., Contribución a la crítica de la política social, Universidad Pontificia de Comillas, Madrid, 1993, pp.132-133. 
2. La disolución de las fronteras entre lo público y lo privado. Los proveedores privados asumen inevitablemente un poder de decisión política, aún cuando no les corresponde, y a partir del momento en que una entidad privada recibe fondos públicos, queda sujeta a un mayor control público, perdiendo una parte de sus rasgos más distintivamente privados.

Tradicionalmente, ha habido dos tendencias en torno a la diferenciación entre el sector público y el privado: una que identificaba el servicio público con aquel servicio realizado directamente por un órgano de la Administración, y la privatizadora, que identifica el servicio probienestar con la búsqueda de ganancias y con ánimo de lucro.

García Roca propone elaborar el concepto de servicio público que permita distanciarse de ambas posturas ${ }^{15}$.

El que un servicio sea público no viene determinado por la forma jurídica en que se organiza, sino básicamente *por la naturaleza de su función, *por el origen público de los recursos que lo financian y *por la igualdad de todos los ciudadanos en el acceso.

Así, el término «servicio público» queda definido en el Seminario Taxonómico ${ }^{16}$ como «servicio técnico regulado por el Estado, prestado o producido directamente por este o mediante gestión indirecta, para garantizar la oferta de ciertos bienes de interés general».

\section{III.DIFERENCIAS ENTRE LOS SECTORES}

Veamos ahora más detenidamente las características y diferencias entre los sectores que intervienen en los servicios sociales, desde estructuras institucionales (véase cuadro de la página siguiente).

\subsection{Sector público}

Está representado por las administraciones públicas, así como sus organismos autónomos. El control de estas corresponde a los representantes elegidos por la sociedad, o por individuos o grupos legitimados por el poder político. Las formas de intervención pública son varias: la acción propia directa, acción concertada, subvenciones, desgravaciones, etc.

16 VARIOS AUTORES., Conceptos básicos de Bienestar Social. Seminario Taxonómico, Colegio Oficial de Doctores y Licenciados en Ciencias Políticas y Sociología, Madrid, 1987, pp. 205. 


\begin{tabular}{|c|c|c|c|}
\hline & $\begin{array}{c}\text { SECTOR PÚBLICO } \\
\text { PODER }\end{array}$ & $\begin{array}{l}\text { SECTOR PRIVADO } \\
\text { NOLUCRATIVO } \\
\text { SOLIDARIDAD }\end{array}$ & $\begin{array}{l}\text { SECTOR PRIVADO } \\
\text { MERCANTIL } \\
\text { MERCADO }\end{array}$ \\
\hline Filosofía & Justicia & $\begin{array}{c}\text { Filantropía, } \\
\text { Solidaridad } \\
\text { Altruismo }\end{array}$ & Beneficio \\
\hline Representa & Mayoría & Minoría & Propietarios \\
\hline $\begin{array}{l}\text { Base legal del } \\
\text { servicio }\end{array}$ & Derecho & Gratuidad & $\begin{array}{c}\text { Cuota por el } \\
\text { servicio prestado }\end{array}$ \\
\hline $\begin{array}{l}\text { Fuente de } \\
\text { financiación }\end{array}$ & Impuestos & $\begin{array}{c}\text { Cuotas, } \\
\text { Subvenciones }\end{array}$ & $\begin{array}{c}\text { Pago de clientes } \\
\text { o terceros }\end{array}$ \\
\hline $\begin{array}{l}\text { Determinación } \\
\text { de funciones }\end{array}$ & Prescrita por ley & $\begin{array}{l}\text { Seleccionada } \\
\text { por grupo }\end{array}$ & $\begin{array}{l}\text { Elegida por } \\
\text { propietarios } \\
\text { directivos }\end{array}$ \\
\hline Objetivo & Interés general & $\begin{array}{l}\text { Limitada por } \\
\text { ubicación o } \\
\text { ideología }\end{array}$ & $\begin{array}{l}\text { Limitada a } \\
\text { aquellos que } \\
\text { pueden pagar }\end{array}$ \\
\hline $\begin{array}{l}\text { Fuente de } \\
\text { autoridad }\end{array}$ & Cuerpo legislativo & $\begin{array}{l}\text { Reglamento o } \\
\text { estatutos }\end{array}$ & Propietarios \\
\hline $\begin{array}{l}\text { Estructura } \\
\text { administrativa }\end{array}$ & $\begin{array}{l}\text { Amplia, } \\
\text { Burocrática }\end{array}$ & $\begin{array}{c}\text { Pequeña, } \\
\text { Burocrática }\end{array}$ & Burocrática \\
\hline Responsabilidad & $\begin{array}{l}\text { Ante el electorado } \\
\text { a través de un } \\
\text { cuerpo legislativo }\end{array}$ & $\begin{array}{c}\text { Ante los miembros } \\
\text { a través del consejo } \\
\text { de dirección y ante } \\
\text { los fundadores }\end{array}$ & $\begin{array}{c}\text { Ante los } \\
\text { propietarios }\end{array}$ \\
\hline
\end{tabular}

Fuente: Adaptación de Knapp, M., La economía de los servicios sociales, EUGE, Barcelona, 1990, pp. 183.

\subsection{Sector privado mercantil (comercial)}

Representa el mercado y el dinero. Desarrolla actividades con fin lucrativo y son controladas por propietarios privados.

\subsection{Sector privado no lucrativo (voluntario)}

Representa la solidaridad, que constituye en palabras de Pérez Díaz, el «cemento emocional y moral de la integración social, que implica un sentimiento y un compromiso moral con una identidad colectiva. Ahora bien, los sentimientos y los compromisos morales tienen como 
sujetos en último término a los individuos, de ninguna forma a las organizaciones ${ }^{17}$. Victoria Camps dice de la solidaridad que es una virtud, que debe ser entendida como condición de justicia y como aquella medida que viene a compensar las imperfecciones de esta, y que serían tres: ${ }^{18}$

1. Porque debe atender las necesidades e intereses generales y toma cuerpo en la ley; esto es, en la intransigencia, la uniformidad y el castigo.

2. La justicia nunca es total ni llega a realizarse del todo, ha de ser compensada con sentimientos de ayuda, amistad, colaboración, reconocimiento del otro, etc.

3. Porque la vida misma es injusta y la igualdad natural es un mito. A este respecto Cobo Suero distingue dos tipos de solidaridad:

- Subjetiva, que nace de la persona misma, que se compromete en acciones solidarias porque se siente interiormente impelida a ello y decide hacerlo libremente. Esta sería una responsabilidad individual y colectiva que correspondería a la sociedad civil, que ha de completar las carencias dejadas por la solidaridad objetiva en materia de justicia social. Esta es la misma idea de Victoria Camps, que comentamos anteriormente.

- Objetiva: por la que se impone a los ciudadanos algo que han de cumplir, con independencia de que se sientan o no solidarios con los demás a hacerlo. Esta es responsabilidad del Estado ${ }^{19}$.

\section{MARCO LEGISLATIVO}

Vamos a ver a continuación el marco legislativo a través del cual es posible que todos los sectores puedan participar y desarrollarse. El primer referente es el marco constitucional y en él hemos de tener en cuenta:

- El artículo 9.2: «Corresponde a los poderes públicos promover las condiciones para que la libertad y la igualdad del individuo y de los grupos en que se integra sean reales y efectivas; remover los obstáculos que impidan o dificulten su plenitud y facilitar la participación de todos los ciudadanos en la vida política, económica, cultural y social».

- El artículo 22: «Derecho de asociación».

- El artículo 34: «Derecho de fundación, para fines de interés general».

17 PÉREZ DÍAZ, V., El retorno de la sociedad civil, Instituto de Estudios Económicos, Madrid, 1987 , pp.37.

I* CAMPS, V., K., Virtudes públicas, Espasa Calpe, Madrid, 1990, pp.34-35.

(1) COBO SUERO, J.M., op.cit. pp.135. 
- El artículo 38: Libertad de empresa.

- En cuanto a la legislación autonómica, hemos de tener en cuenta el marco de las leyes de Servicios Sociales. He tenido en cuenta lo que dice la mayoría y lo que dice la minoría, que es el fiel reflejo, pienso, de las nuevas condiciones que se están dando y que tiene mucho que ver con este debate ${ }^{20}$.

\subsection{Iniciativa social}

Todas las leyes de servicios sociales contemplan la iniciativa social, que colaborará con el sistema público de servicios sociales que se está regulando (iniciativa privada sin fin de lucro). Aunque los ser-

LEY 6/1982, de 20 de mayo sobre Servicios Sociales, B.O. del País Vasco de 2 de junio de 1982.

LEY FORAL 14/1983, de 30 de marzo sobre Servicios Sociales, B.O. de Navarra, de 8 de abril de 1983.

LEY 1 l/1984, de 6 de junio de Servicios Sociales, B.O. de la Comunidad de Madrid, de 23 de junio de 1984.

LEY 8/1985, de 9 de diciembre de Servicios Sociales, B.O. de la Región de Murcia, de 19 de diciembre de 1985.

LEY 26/1985 de 27 de diciembre de Servicios Sociales, D.O. de la Generalidad de Cataluña, de 10 de enero de 1986.

LEY 3/1986, de 16 de abril de Servicios Sociales de Castilla-la Mancha, D.O.C.M. de 20 de mayo de 1986.

LEY 9/1987, de 11 de febrero, de Acción Social de Baleares, BOE $n^{\circ} 53$, de 28 de abril de 1987.

LEY 4/1987, de 25 de marzo, de Ordenación de la Acción Social de Aragón, BOE n 86, de 10 de abril de 1987.

LEY 5/ 987, de 11 de abril, de Servicios Sociales del Principado de Asturias, BOE $n^{\circ} 137$, de 9 de junio de 1987.

LEY 5/1987, de 23 de abril, de Servicios Sociales, D.O. de Extremadura ${ }^{\circ} 37$, de 12 de mayo de 1987.

LEY 9/1987, de 28 de abril, de Servicios Sociales de Canarias, BOE n 126, de 27 de mayo de 1987.

LEY 2/1988, de 4 de abril, de Servicios Sociales de Andalucía, BOJA no 29 , de 12 de abril de 1.988.

LEY 18/1989, de Acción Social y Servicios Sociales de Castilla-León, en Boletín Informativo.

LEY DE LA GENERALITAT VALENCIANA 5/1989, de 6 de julio de Servicios Sociales de la Comunidad Valenciana, DOGV de 12 de julio de 1989.

LEY $2 / 1990$, de 10 de mayo, de Servicios Sociales de la Comunidad Autónoma de la Rioja, BOE $n^{\circ} 132$, de 2 de junio de 1990.

LEY 5/1992, de 27 de mayo, de Acción Social de Cantabria, BOE n ${ }^{\circ}$ 181, de 29 de julio de 1992.

LEY 4/1993, de 14 de abril de Servicios Sociales de Galicia, en Cediss n ${ }^{\circ} 45$, Legislación sobre Servicios Sociales, pp. 6-22. 
vicios sociales sean de responsabilidad pública, ello no puede suponer que la titularidad y la gestión de los mismos no pueda ser ostentada por la iniciativa social. Ahora bien, la intervención de esta última ha de desarrollarse dentro de las coordenadas establecidas por las administraciones públicas.

La iniciativa social se contempla en las leyes como subsidiaria ${ }^{21}$ y complementaria de las actuaciones de la administración pública.

Aunque con algunas matizaciones, todas las leyes coinciden en que la administración pública colaborará con la iniciativa social cuando esta cumpla con una serie de requisitos, quedando, por tanto, sometida a determinadas limitaciones:

a) Prestar el servicio o la actividad en el territorio de la Comunidad Autónoma de referencia.

b) Su fin primordial ha de ser el cumplimiento de una función social.

c) Ausencia de ánimo de lucro.

d) Sometimiento al control e inspección de sus actuaciones por parte de la Administración Pública.

e) Adecuación a las normas y a la planificación general de lo que determine la Administración Pública.

f) Funcionamiento interno democrático y garantía de que es así.

g) Inscripción en un Registro de Entidades y Centros, que a tal efecto se establecerá en los órganos correspondientes.

\subsection{Iniciativa privada con fin lucrativo}

Respecto a la intervención de la iniciativa privada con fin lucrativo, las leyes guardan un silencio casi absoluto, excepto en algunas de ellas, aunque de ello no se puede deducir que se prohíba su actuación dentro del campo de la acción social.

Haremos referencia a la ley de Galicia que es la más reciente, concretamente de 1993. Es producto de la derogación de la existente desde 1987, justificándose en su introducción los motivos de dicha derogación: «la propia evolución de la realidad que trataba de ordenar la anterior y las limitaciones del propio texto que se deroga y especialmente la ordenación de las entidades prestadoras de servicios sociales y del voluntariado social, y que hace referencia a que, si bien los servicios sociales se constituyen como un servicio público, no puede

21 La subsidiariedad hace referencia a la necesidad de cubrir las lagunas que se producen en la prestación de servicios. Para Beltrán Aguirre (1992, 365), el término «subsidiariedad» no debe entenderse como secundario, provisional o subordinado, sino que ha de entenderse en una relación de complementariedad ya que ambas aportan algo propio y diferenciado que se complementa. 
«ahogar la creatividad e iniciativa de la sociedad sino, muy al contrario, que la fomente, coordine, regule y colabore, como una parte más integrante en el conjunto, que, considerado en su globalidad, es de responsabilidad pública». Así, de un modo explícito, se reconoce no sólo la iniciativa social carente de fin de lucro, sino también la iniciativa privada lucrativa, lo RECONOCE también en sus principios inspiradores, quedando ambas reguladas como entidades prestadoras de servicios sociales junto con la administración autonómica y las entidades locales.

\section{VENTAJAS / LIMITACIONES DE CADA UNO DE LOS SECTORES}

Estas ventajas y limitaciones de las que hablaremos es lo que justifica el que la provisión de Servicios Sociales no pueda o no deba hacerse casi exclusivamente por uno de ellos, sino por la combinación adecuada de todos, ya que la política social del Estado del Bienestar hay que entenderla en un contexto más amplio, donde puedan existir una gran variedad de combinaciones económicas y organizativas para la prestación, financiación y regulación de los sistemas de bienestar.

\subsection{El sector público}

El sector público se enfrenta a la necesidad de compatibilizar un conjunto de demandas sociales que implican la extensión y la calidad de los servicios públicos y su aceptación a las nuevas necesidades de los 90, con la contención global del gasto público, para evitar disfuncionalidades. López y Utrilla piensan que este desafío se ha comenzado a abordar a través de distintos planteamientos generales:

1. Revisando los objetivos y prioridades existentes en los programas de gasto público.

2. Mejorando la eficiencia de los provisión de bienes y servicios públicos.

3. $\mathrm{Y}$ atribuyendo un mayor protagonismo a la iniciativa privada en la solución de las necesidades colectivas ${ }^{22}$.

La administración tiene un carácter instrumental, puesta al servicio de los intereses generales de los ciudadanos; pero, aunque tenga la responsabilidad, no interviene en todos los sectores de actividad de los servicios sociales; por tanto, si ésta no interviene, alguien lo tiene

22 LÓPEZ, M.T. y UTRILLA, A., El sector puiblico español (Organización, gestión y aspectos económicos), Actualidad Editorial, Madrid, 1991, pp.110. 
que hacer. Es ahí donde hay espacio para la intervención de los otros sectores, a través de distintas fórmulas. Nos podríamos preguntar qué factores o qué hechos motivan que los poderes públicos intervengan en unos problemas y en otros no.

1. Escasez de recursos personales, económicos y materiales de la administración que tendría responsabilidad de hacerlo.

2. Falta de voluntad o interés político por los problemas sobre los que debe actuarse. Se ha señalado que una causa podría estar en la falta de capacidad intelectual o técnica de los funcionarios políticamente responsables del diseño de políticas públicas.

3. Una legislación o reglamentación defectuosa o inexistente sobre el tema que impide o dificulta una actuación eficiente.

4. La presión por parte de los medios de comunicación o de sectores afectados por un problema particular y singular, que insisten en traspasar al sector público los costes de su problemática sectorial ${ }^{23}$. En general, un problema nuevo forma parte de la actuación pública cuando:

a. El tema ha llegado a una situación crítica y es difícil que siga siendo ignorado.

b. El tema provoca una situación emotiva que atrae la atención de los medios de comunicación.

c. El problema adquiere una importancia global, teniendo en sus inicios unas dimensiones y efectos muy limitados.

d. Los problemas alcanzan gran notoriedad pública por conectar con tendencias o valores vigentes en la sociedad.

En relación a las ventajas de los servicios estatales, Jhonson señala, entre otros ${ }^{24}$ :

1. La oportunidad para una planificación social amplia. El Estado está en situación de adoptar, mejor que ningún otro sector, una visión completa de la dirección de la política social y de establecer prioridades para su desarrollo futuro. La igualdad, por ejemplo, es más probable que se logre mediante la planificación social que a través de actividades no planificadas realizadas por miles de proveedores, ninguno de los cuales está interesado especialmente en ella. La redistribución no ocurrirá por sí misma, es preciso que sea deliberadamente planificada.

2.3 SUBIRATS, L., Analísis de políticas puiblicas y eficacia de la Administración, Ministerio para las Administraciones Públicas, Madrid, 1989, pp.53. y SALA PRAT, G., El negocio de la pobreza o la Utopia del Bienestar, Asociación para la Defensa de la Igualdad Social, Barcelona, 1994, pp. 127.

24 JHONSON, N., El Estado de Bienestar en transición. La teoría y la p'ractica del pluralismo del bienestar, Ministerio de Trabajo y Seguridad Social, Madrid, 1990, pp.214-220. 
2. La ventaja de lo anterior es que al haber una planificación específica puede ser cuestionada y evaluada. Se pueden exigir responsabilidades a los que son responsables del mismo. El término responsabilidad sugiere la idea de "tener en cuenta» las consecuencias de las acciones de uno sobre el bienestar de los demás. La importancia que ha de concederse a los intereses de los demás dependerá de la cultura, el contexto y la naturaleza de la relación. Pero los poderes públicos, según señala Donahue, han de ser responsables por tres motivos ${ }^{25}$ :

a. Porque algunas funciones cruciales para la sociedad deben desarrollarse de forma colectiva.

b. Porque el público, en general, está expuesto a descuidos por parte de las autoridades, en relación a que estas se tomen debidamente en cuenta sus intereses.

c. El individuo es vulnerable ante los poderes públicos, aspecto que la historia ilustra en abundancia y que las constituciones de los distintos países tratan de remediar.

La responsabilidad es una característica de los servicios estatales en general, y es una ventaja de los servicios públicos sobre los servicios proporcionados por otros sectores. Aunque la responsabilidad en los servicios estatales no funcione, es una útil salvaguarda y existen procedimientos para presentar quejas y luchar contra las decisiones que se adoptan.

3. Otras característica, y que comparte con los sectores voluntario e informal, es que sus actuaciones normalmente responden a las necesidades, lo que se contrapone con el sector comercial, que responde a la demanda, a la capacidad de pagar.

4. El Estado puede asegurar una cobertura más amplia y más igualitaria que cualquiera de los otros sectores.

5. Puede actuar sobre las causas de los problemas sociales y hacer frente a los costes sociales que surgen de los cambios tecnológicos, industriales y económicos. Ello no lo hace el sector comercial, porque lo más probable es que la prevención funcione en contra de sus intereses comerciales al reducir el número de sus clientes. Las organizaciones voluntarias podrán adoptar estrategias preventivas, pero la prevención requiere, para tener éxito, una aproximación coordinada y cooperativa, que no es precisamente una de las características de la provisión voluntaria.

6. Otra característica distintiva de los servicios públicos es que generalizan el altruismo, permitiéndonos tener comportamientos altruistas para con los extraños. Titmuss se refiere a esto como una 
«amabilidad anónima». Aunque el altruismo supone de antemano la libertad de decidir si dar o no dar y al estar incrita esta idea en que la política de bienestar se considera repuesta a los derechos sociales, la misma despoja al donante de esa libertad, al suponer que es un deber, una obligación para quienes poseen recursos suficientes, dar a quien se halla en estado de necesidad.

\subsection{Sector privado no lucrativo}

Este es lo que para Ugo Ascoli constituye el ámbito de las «relaciones privado-sociales», son los sujetos formales y constituyen el área de las «solidaridades asociativas» ${ }^{26}$, que tienen un reconocimiento público y donde es posible también encontrar una relación contractual. En general, este sector es muy complejo y heterogéneo y las entidades que lo componen suelen definirse por exclusión de la provisión pública y el mercado. Las entidades pertenecientes a este sector tienen denominaciones muy diversas: entidades privadas sin fin de lucro, organizaciones no gubernamentales (esta es la denominación que parece haberse impuesto en el ámbito internacional), entidades de iniciativa social, tercer sector, entidades sociovoluntarias, entidades asistenciales, entidades solidarias, $y$, además, pueden tener una naturaleza jurídica muy variada, ya que pueden constituirse en asociaciones, fundaciones, federaciones, cooperativas, etc.

Tradicionalmente, este sector se ha identificado con la prestación se servicios que ni el interesado, ni el sector público, pueden proveer de forma satisfactoria, por la incapacidad de pago de aquellos a los que va destinado el servicio, bien por insuficiencia de recursos o voluntad política por parte del sector público ${ }^{27}$.

Seguimos, para el desarrollo de este sector, la clasificación que hace Ugo Ascoli, que dice nos podemos encontrar con tres tipos de sujetos formales: las organizaciones voluntarias, los grupos de autoayuda y el voluntariado social ${ }^{28}$.

27 ROVIRA I FORNS., "Contribución de las entidades no lucrativas al bienestar social» en Documentación Social ${ }^{\circ} 71$, abril-junio, 1988, pp. 178.

2s ASCOLI, U., «Estado de bienestar y Acción voluntaria» en Revista Española de Investigaciones Sociológicas, $\mathrm{n}^{\circ} 38,1987, \mathrm{pp} .134$. 


\subsubsection{Organizaciones voluntarias}

Las organizaciones voluntarias han desempeñado siempre un papel de gran importancia en la sociedad europea, en la prestación de servicios sociales y humanos en general.

Y tienen una serie de características:

1. Su sistema de formación es voluntario.

2. Su sistema o modo de gestión es el autogobierno a través de sus propios órganos y en cuanto a sus actividades y el modo de distribuir sus recursos.

3. Su sistema de financiación es a través de aportaciones voluntarias de sus miembros, destinados a mantenerlos; aunque esta característica queda actualmente diluida, por cuanto muchas de las organizaciones funcionan por las subvenciones que perciben de las administraciones públicas.

4. Las motivaciones que guían su funcionamiento no deben perseguir ningún tipo de beneficio de índole comercial.

5. Presentan, por lo general, un alto grado de especialización, correspondiendo al sujeto público la obligación de proporcionar los servicios básicos o generales.

\subsubsection{Grupos de ayuda mutua}

La autoayuda es una vieja idea reavivada en los últimos años. Los grupos de autoayuda son fruto de iniciativas voluntarias y están formados por personas que tienen un problema o una preocupación compartida, las cuales se unen para el apoyo mutuo y la provisión de servicios a sus miembros y que son conscientes de que sus necesidades no pueden ser cubiertas a través de las instituciones existentes. $\mathrm{La}$ distinción entre proveedores y receptores es vaga e inexistente ya que son los propios miembros los que controlan la organización y la definición de los problemas y las necesidades.

Es difícil hacer una valoración unitaria de estos grupos; no obstante, se afirma que son portadores de una nueva cultura de satisfacer las necesidades que permite superar graves lagunas y deficiencias de los aparatos de bienestar, demasiado rígidos, impersonales, burocráticos y de escasa eficacia.

Los grupos de autoayuda prestan acogida, información, apoyo; aunque pueden prestar también una serie de actividades opcionales como la promoción de servicios, la mentalización social, acciones preventivas, reivindicación ${ }^{29}$.

29 AZUA, P., «Opciones de política interna por parte de las ONGs» en Varios Autores: Organizaciones Voluntarias e intervención social, Acebo, Madrid, 1989, pp.54-57. 
En cuanto a los tipos de grupos de ayuda mutua, hay autores que diferencian entre grupos de apoyo orientados principalmente a la ayuda directa de sus miembros y los que están orientados básicamente a la defensa social y acción política, ya que ambos operan de distinta forma, porque tienen fines diferentes.

Este es un tema popular entre los pluralistas del bienestar, tanto la izquierda como la nueva derecha apoyan la autoayuda, porque es vista como una reacción saludable contra el Estado de Bienestar en que predominan burócratas y profesionales, ya que ésta no es buena aliada para cuando hay que hacer frente a necesidades más personales e individuales y porque es compatible con la descentralización (es una actividad típicamente local) y la participación, ya que por su propia naturaleza es participativa.

\subsubsection{Voluntariado}

El voluntariado, en su sentido más puro, son gentes que no reciben remuneración por lo que hacen, aunque puedan ser reembolsados por los gastos que realicen en el ejercicio de su acción.

Aznar, como jurista y con sus clásicas precisiones conceptuales, advierte de la conveniencia de utilizar más que la expresión «voluntariado» o "voluntario», la de «trabajo benévolo», ya que la voluntariedad no es algo que distinga la actividad no retribuida de la retribuida, sino que es común a ambas, ya que aquella tan sólo se opone al trabajo obligatorio o forzoso ${ }^{30}$.

Actualmente, es un tema muy polémico en España, aunque muchas Comunidades Autónomas se están dotando de Leyes de Voluntariado, así como la Administración Central, no lo es tanto en otros países europeos, donde existe una larga y amplia tradición de voluntariado. Su manifestación más pura es la solidaridad y compartir los problemas sociales. Es preciso, no obstante, que se redefina su papel en la sociedad de cambio actual, y partir de que existen estructuras organizativas e institucionales, y no actuar «por su cuenta».

De todas las maneras, nos podríamos preguntar si el voluntariado forma parte de nuestra cultura civil. Pienso que esa es línea de investigación empírica que está aún por desarrollar.

Pasamos a ver ahora las funciones que desempeña este sector. Aunque son bastantes las he agrupado en cuatro para hacer mas fácil su comprensión:

3) AZNAR, M., «La legislación autonómica de acción social. Análisis jurídico» en $V$ Informe sociológico sobre la situación social en España, $2^{\circ}$ volu. Fundación Foessa, Madrid, 1994, pp. 1872. 
1. Cumplen una función importante en la sensibilización y estímulo de la conciencia ciudadana ante las problemáticas sociales; idea, esta, fundamental para actuar sobre las causas de los problemas sociales y de las desigualdades, función que Jarré denomina de «guardián de los valores» y que consiste en preservar aquellos valores tan desprestigiados y paradójicamente ensalzados actualmente como la solidaridad, la filantropía, la participación, el pluralismo, la protección de las minorías, etc. ${ }^{31}$. Una comunidad dependiente resulta más dócil y controlable, pero conduce al «individualismo comunitario» y a la impermeabilidad frente a los problemas que son vividos y percibidos como «del Estado», y cualquier política de prevención, rehabilitación y reinserción estará condenada al fracaso si no se cuenta con comunidades receptivas.

2. Cumplen una función histórica de denuncia y presión frente a la administración y la sociedad, como único o principal propósito, intentando cambiar las actitudes públicas y haciendo campaña para una mejor provisión de los servicios. A menudo, se convierten en portavoces de grupos sociales marginales, con escasa o nula capacidad de organización, desempeñando una importante acción de defensa de estas personas, vigilando para que las personas obtengan aquello a lo que tienen derecho. Hay grupos que combinan la provisión de servicios con la denuncia y la presión.

A este respecto, dice Pilar Malla que la función de denuncia se hace necesaria desde la situación económica actual y la repercusión que tiene en los sectores menos favorecidos, no debiéndose olvidar que en muy pocas ocasiones una administración ha dado a conocer la pobreza de su propio pueblo ${ }^{32}$. Tenemos el ejemplo del revuelo y las manifestaciones públicas que causó la investigación realizada por Cáritas, cuando dio a conocer a la opinión pública la existencia en España de ocho millones de pobres.

3. Otra función que el sector voluntario realiza es una función complementaria, asumiendo servicios delegados o concertados, bien con sus propios recursos bien como gestoras de recursos públicos, bien con fórmulas mixtas. Cumplen un papel complementario cuando están prestando servicios de distinta naturaleza de aquellos dados por las administraciones publicas y cumplen también una función suplementaria de la provisión estatal cubriendo coyunturalmente servicios o sectores desatendidos o atendidos insuficientemente hasta que sean asumidos por aquella.

3I JARRÉ, D., Boletín del Comité Español para el Bienestar Social, n 16-17, Madrid, 1988. pp.3

32 MALLA, P., «El Trabajo Social en las Instituciones privadas» en Documentación Social $\mathrm{n}^{\circ}$ 64, Madrid, 1986, pp.128. 
Una tercera situación es aquella en la que las organizaciones voluntarias son las únicas o las principales proveedoras de un servicio.

4. Tienen una función innovadora, yendo por delante de los poderes públicos, convirtiéndose en un instrumento de ensayo que permita a aquellos «operar» con más seguridad. A las organizaciones voluntarias se les califica como poseedoras de una mayor agilidado rapidez para movilizar recursos y para despertar iniciativas nuevas, suscitando respuestas alternativas ante nuevas necesidades. Hay que recordar que las organizaciones voluntarias han sido en numerosas ocasiones pioneras tanto en la detección de necesidades, canalizándolas al sector público o bien cubriéndola con sus propios medios; muchos de los recursos actuales, asumidos por la provisión pública (ayuda a domicilio, pisos de acogida, miniresidencias, etc.) fueron introducidos y utilizados por entidades privado-sociales. Así lo confirma Sills: «en muchos países la mayor parte de los servicios cuya responsabilidad asume hoy día el gobierno los iniciaron asociaciones voluntarias ${ }^{33}$.

Ahora entramos a ver las limitaciones o críticas que a este sector se le atañen:

1. Dependencia creciente de la financiación estatal, que da lugar a cuestionarse si ello puede suponer una amenaza para la independencia de las mismas, pero éste es uno de los precios que hay que pagar por ello. Las organizaciones sociales son cada vez más agentes del propio gobierno, aumentando el control sobre las mismas. Esta tendencia ha sido potenciada en parte por el propio sector público, que ha considerado ventajoso fomentar la provisión de servicios a través de entidades sociales, a las que financia en base a subvenciones diversas o conciertos, que es lo que se ha dado en llamar el estado contratante.

Demetrio Casado es uno de los que se muestra un tanto crítico con las organizaciones voluntarias, cuando dice «la mayoría se han enganchado a la ubres subvencionadoras que les ofrecen las administraciones públicas [...]. De este modo se instaura un régimen de dependencia que no contribuye al fomento de las organizaciones voluntarias, sino a su domesticación» o también «cuando el poder público convoca subvenciones orientadas por sus propios criterios y las concede a entidades próximas o satélites no impulsa ni fomenta la iniciativa social, sino que se reproduce a sí misma».

Todo ello da lugar a una serie de fenómenos desnaturalizadores, que esterilizan la creatividad de aquellas al menos en tres sentidos:

i.3 SILLS,D., «Asociaciones Voluntarias» en Enciclopedia Internacional de las Ciencias Sociales, Volumen I, Aguilar, Madrid, 1976, pp.626. 
a. La oferta de recursos suele hacerse de una forma muy reglamentada; ello propicia que las organizaciones voluntarias no se guíen tanto por su apreciación de las necesidades, cuanto por las posibilidades de la oferta.

b. La burocratización de los procedimientos por parte del sector público, en su relación con el sector voluntario, incide en la burocratización de éste.

c. Otras veces, las entidades voluntarias tienden a configurar su demanda o a reconvertirla de acuerdo con las prioridades gubernamentales, para aumentar las posibilidades de lograr las subvenciones, lo cual puede distorsionar sus actividades.

2. Cuando se constituyen en organizaciones de autoayuda parecen gozar de escasa difusión entre las capas más menesterosas y necesitadas de la población, por lo cual parecen constituir un medio más puesto al alcance de los grupos sociales que ya disfrutan de relativas ventajas con respecto al acceso a estructuras profesionales y de servicios y a la utilización de las mismas.

3. Cuanto más consolidada está una organización y más larga tradición tenga, más probable será que haya problemas de fragmentación, despilfarro, duplicidades, burocratización, etc.

4. Lo que comienza siendo un servicio voluntario, con profesional voluntario, acaba profesionalizándose, con lo que se incrementa notablemente el costo de los mismos.

Hay también posturas más críticas que piensan que la función política del sector voluntario es la no solución de problemas. El sector público utilizaría al sector voluntario para hacer políticamente soportable conflictos que, ni él mismo, ni, obviamente, el mercado pueden resolver. El sector público, promoviendo el papel del sector voluntario, diluye o esquiva las responsabilidades que en caso contrario le exigirían los ciudadanos.

\subsection{El sector privado lucrativo (mercado)}

El sector privado lucrativo tiene una característica muy singular respecto a los otros sectores, y es que responde a la demanda solvente (con capacidad de pagar), no a la necesidad. El interés por la ganancia lleva a interesarse por satisfacer cualquier clase de demanda solvente. Es más, puede llegar a correr el riesgo de perpetuar o crear necesidades para autosostenerse.

Una de las virtualidades que se le adjudican al mercado es la libertad de elección, pero ésta realmente sólo la tienen quienes poseen ingresos suficientes, y ello hoy es difícil, por la situación de un desempleo masivo y por la inestabilidad y precariedad de los empleos. 
La libertad de elección sólo existe si hay capacidad económica, quedando excluidos los que no la tienen. Pero si la libertad individual depende de la capacidad de participar en el mercado, ¿qué ocurre con los que están excluidos por falta de recursos?. La libertad política puede sonar a hueco a aquellos que no pueden pagar la factura del médico, de la luz, o que sólo pueden encontrar un alojamiento por debajo del nivel medio. La libertad de hacer sin los servicios esenciales es una libertad a la que la mayoría de las personas no tendrán acceso. La intervención estatal es esencial para garantizar la libertad de los pobres, los desempleados, los enfermos crónicos, la infancia desasistida, los sin techo, etc.

La dinámica y la lógica del mercado tiende a mostrarnos continuamente sus Carencias, no satisface necesidades vitales importantes para todos los ciudadanos: sanidad, educación, servicios sociales, vivienda, protección del medio ambiente, protección civil, transporte público, actividades e instalaciones culturales y deportivas, protección del patrimonio histórico, etc., sus Limitaciones, como lo demuestra la competencia desleal, la protección del consumidor, la legislación sobre publicidad engañosa, la legislación antimonopolios, etc., y sus Desigualdades, porque el mercado por sí sólo no garantiza una situación de empleo, o un sistema de subsistencia digno, como tampoco garantiza una enseñanza o salud básica o especializada, para la totalidad de los ciudadanos que la requieran ${ }^{34}$.

Actualmente, desde ninguna postura se propone dejar al mercado para que este reparta bienes y servicios de acuerdo con la capacidad de pago de cada uno, pues esta propuesta sería inviable desde todos los puntos de vista, la propuesta de los que abogan por una mayor presencia de éste iría encaminada a una intervención selectiva por parte de los poderes públicos, no su abstención; esto es, no pagar el bienestar de todos, porque al final son sólo unos pocos los que no se podrían valer frente al mercado, sin dejar que éste provea y pagar la cuota correspondiente a los más débiles y pobres. Consecuencia: pagar menos impuestos aumentaría la eficiencia y la elección. Pero con este sistema queda claro que el que es receptor de esa «cuota» está en condiciones de desigualdad, pero ello, dicen los liberales a ultranza, ya es «normal» en sociedades que han reconocido en sus constituciones el derecho de propiedad y la libre empresa. Este es el debate añejo y actual sobre el universalismo y la selectividad. 


\subsection{Sector informal}

Este sector está compuesto por lo que se denomina las redes de apoyo naturales, constituida por la familia, los parientes, los amigos y los vecinos. Dentro de los dos tipos de ámbitos de las relaciones sociales de los que habla Ugo Ascoli, éste sería el ámbito de los «mundos vitales», representado por los sujetos informales y hace referencia a las relaciones que los individuos mantenemos con otros individuos como simples seres humanos. Es el principal referente para toda persona y ha constituido desde siempre formas privilegiadas de protección social. En la geografía de la protección, se han generado abundantes experiencias que, basadas en la reproducción de un clima familiar, están orientadas a la resocialización (comunidades terapéuticas, viviendas tuteladas, mini-residencias, etc. ${ }^{35}$. También el acogimiento familiar para menores y ancianos va en esta dirección.

Actualmente, la cuantificación precisa de este sector resulta problemática por dificultades de medida y de pruebas no uniformes, ya que existen una gran variedad de tipos de familias y se desconocen muchos aspectos de la misma en cuanto a los lazos de solidaridad existentes entre el círculo amplio de parientes y la unidad familiar, la influencia del ámbito comunitario sobre la vida familiar, etc., tal y como manifiestan Iglesias y Flaquer en su artículo sobre «Familia y análisis sociológico: el caso de España» ${ }^{36}$.

Actualmente, se asiste a un interés creciente por el apoyo social, que puede ser prestado por «Redes formales» (autoayuda) y «Redes informales», que son aquellas relaciones sociales que emergen del contexto de forma natural y se comparte una responsabilidad por el bienestar de los otros.

En general, hay tres tipos de apoyo:

- Emocional: que se ha definido como sentimiento de pertenencia, de ser amado, de poder confiar en alguien, disponer de alguien con quien poder hablar.

- Tangible o instrumental: que se ha definido como prestar ayuda directa o servicios (ayuda doméstica, dinero, cuidar de los niños, etc.). Es efectiva cuando el receptor percibe la ayuda como adecuada, pero puede tener efectos negativos si el receptor siente amenazada su libertad o si fomenta sentimientos de estar en deuda.

- Informacional: que es el proceso a través del cual las personas buscan información, consejo y/o guía, que las ayude a resolver sus problemas. Tanto este apoyo como el tangible o instrumental pue- 
den considerarse, asimismo, como apoyo emocional, siempre que no se den por obligación (como cuando es prestado por un profesional).

La contribución de este sector informal del que estamos hablando no cabe duda de que es considerable en el caso de los menores, ancianos y minusválidos. Pero la responsabilidad sobre los mismos no está distribuida de igual manera. Puede decirse que la asistencia es prestada mayoritariamente por mujeres. Finch y Groves ${ }^{37}$ dicen que la asistencia comunitaria=asistencia familiar=asistencia femenina, con el impacto que ello supone para la vida personal de las mujeres. La mujer es la que tradicionalmente ha sido la cuidadora de la familia: las esposas cuidan de los esposos, las madres de los niños, las hijas de los padres ancianos o hermanos incapacitados.

La política social tiende a basarse en una visión tradicional de la familia nuclear: dos adultos casados, con el hombre como principal fuente de ingresos y con dos o tres hijos. Pero esta visión tradicional no se corresponde con la realidad contemporánea, por la amplia participación de la mujer en el mercado de trabajo y los cambios en la estructura familiar (familias monoparentales, incorporación de la mujer al trabajo y la educación, etc.). Las consecuencias de estos cambios ya se están haciendo patentes, porque es difícil que la mujer, con todas las nuevas responsabilidades que está adquiriendo, pueda seguir asumiendo además su papel tradicional. Las políticas que no toman en cuenta estos cambios sólo pueden ser irreales y fracasar a la hora de cumplir sus objetivos. En cualquier caso, Johnson dice que «el objetivo principal de la política social no debería ser presionar a las personas para que se hagan cargo de responsabilidades extra, sino proporcionarles una alternativa realista, de manera que la gente que escoja cuidar de sus familiares más débiles debe recibir todo el apoyo necesario, pues el apoyo que saben que tendrán a su disposición es una de las consideraciones que la gente tiene en cuenta al hacer su elección. Aquellos que eligen no proporcionar una asistencia directa deben tener seguridad en que existen servicios alternativos aceptables, pues si el pluralismo del bienestar tiene algún mérito debe ser el de ampliar el campo de elección, no el restringirlo ${ }^{38}$. Esta idea es también expresa por Doyal y Gouhg ${ }^{39}$.

Respecto a la ayuda prestada por amigos y vecinos, se ha hecho bastante menos investigación, aunque no cabe duda de que es fuente importante de ayuda para muchas personas, pero los amigos se dife- 
rencian de la familia y parientes en que uno los elige, a la familia no, pero el cuidado mutuo no es un elemento inherente en la organización rutinaria de la amistad, ya que no están especialmente bien provistas para suministrar el tipo de cuidados que la asistencia comunitaria conlleva ${ }^{40}$. Además, los servicios proporcionados por vecinos y amigos son tareas simples, que implican tan sólo un compromiso limitado, y que, aunque sean importantes, no sirven de base para constituir un adecuado sustento para el desarrollo de políticas de asistencia comunitaria.

\section{VI.PARA FINALIZAR}

El pluralismo del bienestar o sistema mixto implica el reconocimiento de la complementariedad de cada una de los tres sectores y, a la vez, las imperfecciones e insuficiencia de cada uno de ellos. Cada sector puede resultar eficaz para resolver unas determinadas funciones y puede tener su ámbito, dependiendo de la naturaleza de la necesidad a la que se intente hacer frente o el objetivo que se quiera alcanzar. Ninguno puede ser una alternativa al margen de los otros; sin olvidar que todos tienen sus ventajas y limitaciones, como hemos tratado de exponer.

El Estado, a través de sus administraciones y de las numerosas fórmulas administrativas, tiene que intervenir cuando hay que asegurar la universalidad y la igualdad, propiciando la redistribución, y garantizando un mínimo vital para todos los ciudadanos.

El mercado es necesario para responder a las necesidades que se convierten en preferencias personales a través de medidas individualizadoras, y la competencia en función a la eficiencia de los servicios, pero no resulta eficaz para generalizar la oferta.

El sector voluntario es apropiado para hacer frente a aquellas necesidades que necesitan de proximidad física, ofertada a través de la solidaridad, pero resulta ineficaz para resolver problemas de equidad.

Los que se decantan por el pluralismo del bienestar desean el mantenimiento del Estado del Bienestar, pero quitando peso al Estado como el principal proveedor de servicios, con un mayor peso por tanto de los otros sectores. Su papel seguirá siendo importante en la $f i$ nanciación, planificación, promoción y reglamentación de los servicios. Los pluralistas del bienestar no abogan necesariamente por una reducción del gasto estatal, sino por la redistribución del mismo en 
apoyo de una provisión informal y voluntaria. El pluralismo del bienestar no significa un menor bienestar sino un desplazamiento de la provisión del mismo de un sector a otro, produciéndose no un desmantelamiento del Estado del Bienestar, sino una reestructuración del mismo.

\section{BIBLIOGRAFÍA}

ASCOLI, U., «Estado de bienestar y Acción Voluntaria», en Revista Española de Investigaciones Sociológicas $\mathrm{n}^{\circ} 38,1987, \mathrm{pp} .119-162$.

ASCOLI, U., «Voluntariado organizado y sistema público del «Welfare»: Potencialidades y límites de una cooperación» en Documentación Social $\mathrm{n}^{\circ}$ 71, abril-junio, 1988, pp. 183-203.

AZNAR, M., «La legislación autonómica de acción social. Análisis jurídico» en $V$ Informe sociológico sobre la situación social en España. Sociedad para todos en el año 2000, 2 vol, Fundación Foessa, Madrid, 1994, pp. 1737-1875.

AZÚA, P., «Opciones de política interna por parte de las ONGs» en Varios Autores: Organizaciones voluntarias e intervención social, Acebo, Madrid, 1989, pp. 51-68.

BELTRÁN AGUIRRE, J.L., El régimen jurídico de la acción social pública, Instituto vasco de Administración Pública, Bilbao, 1992.

CAMPS, V., Virtudes Públicas, Espasa Calpe, Madrid, 1990.

CASADO, D., «Las organizaciones sociovoluntarias» en Varios Autores: Organizaciones sociales e intervención social, Acebo, Madrid, 1989., pp. 17-50.

COBO SUERO, J.M., Contribución a la crítica de la política social, Universidad Pontificia de Comillas, Madrid, 1993.

DONAHUE, J.D., La decisión de privatizar. Fines públicos, medios privados, Paidós, Barcelona, 1991.

DOYAL, L. y GOHGH, I., Teoría de las necesidades humanas, Icaria, Barcelona, 1994.

FRIEDMAN, M. y R., Libertad de elegir, Grijalbo, $2^{\mathrm{a}}$ edición, Barcelona, 1980.

GALBRAITH, J.K., La cultura de la satisfacción, Ariel, Barcelona, 1992.

GARCÍA ROCA, J., Público y privado en la acción social. Del Estado del Bienestar al Estado Social, Popular, Madrid, 1992.

HARRIS, D., Justificación del Estado del Bienestar, Instituto de Estudios Fiscales, Madrid, 1987. 
IGLESIAS, J. y FLAQUER, L., «Familia y análisis sociológico: el caso de España» en Revista Internacional de Sociología $\mathrm{n}^{\circ}$ 61, 1993, pp. 57-75.

JARRÉ, D., Boletín del Comité Español para el Bienestar Social, $\mathrm{n}^{\circ}$ 16-17, Madrid, 1988.

JHONSON, N., El Estado de Bienestar en transición. La teoría y la práctica del pluralismo del bienestar. Ministerio de Trabajo y Seguridad Social, Madrid, 1990.

KNAPP, M. .,La economía de los Servicios Sociales. EUGE, Barcelona, 1990.

LEY 6/1982, de 20 de mayo sobre Servicios Sociales, B.O. del País Vasco de 2 de junio de 1982.

LEY FORAL 14/1983, de 30 de marzo sobre Servicios Sociales, B.O. de Navarra, de 8 de abril de 1983.

LEY 11/1984, de 6 de junio de Servicios Sociales, B.O. de la Comunidad de Madrid, de 23 de junio de 1984.

LEY 8/1985, de 9 de diciembre de Servicios Sociales, B.O. de la Región de Murcia, de 19 de diciembre de 1985.

LEY 26/1985 de 27 de diciembre de Servicios Sociales, D.O. de la Generalidad de Cataluña, de 10 de enero de 1986.

LEY 3/1986, de 16 de abril de Servicios Sociales de Castilla-la Mancha, D.O.C.M. de 20 de mayo de 1986.

LEY 9/1987, de 11 de febrero, de Acción Social de Baleares, BOE n 53, de 28 de abril de 1987.

LEY 4/1987, de 25 de marzo, de Ordenación de la Acción Social de Aragón, BOE $n^{\circ} 86$, de 10 de abril de 1987.

LEY 5/1987, de 11 de abril, de Servicios Sociales del Principado de Asturias, BOE $n^{\circ} 137$, de 9 de junio de 1987.

LEY 5/1987, de 23 de abril, de Servicios Sociales, D.O. de Extremadura ${ }^{\circ}$ 37, de 12 de mayo de 1987.

LEY 9/1987, de 28 de abril, de Servicios Sociales de Canarias, BOE n ${ }^{\circ} 126$, de 27 de mayo de 1987.

LEY 2/1988, de 4 de abril, de Servicios Sociales de Andalucía, BOJA n ${ }^{\circ} 29$, de 12 de abril de 1988.

LEY 18/1989, de Acción Social y Servicios Sociales de Castilla-León, en Boletín Informativo.

LEY DE LA GENERALITAT VALENCIANA 5/1989, de 6 de julio de Servicios Sociales de la Comunidad Valenciana, DOGV de 12 de julio de 1989.

LEY 2/1990, de 10 de mayo, de Servicios Sociales de la Comunidad Autónoma de la Rioja, $\mathrm{BOE} \mathrm{n^{ \circ }} 132$, de 2 de junio de 1990. 
LEY 5/1992, de 27 de mayo, de Acción Social de Cantabria, BOE n 181, de 29 de julio de 1992.

LEY 4/1993, de 14 de abril de Servicios Sociales de Galicia, en Cediss n 45 , Legislación sobre Servicios Sociales, pp. 6-22.

LÓPEZ, Ma T. y UTRILLA, A., El sector público español (Organización, gestión y aspectos económicos), Actualidad Editorial, Madrid, 1991.

MALLA, P., «El Trabajo Social en las instituciones privadas» en Documentación social $\mathrm{n}^{\circ} 64$, Cáritas Española, 1986, pp.

MISHRA, R., «El Estado de Bienestar después de la crisis: los años 80 y más allá» en Varios Autores: Crisis y futuro del Estado de Bienestar, Alianza, Madrid, 1993.

PÉREZ DÍAZ, V., El retorno de la sociedad civil, Instituto de Estudios Económicos, Madrid, 1987.

PÉREZ DÍAZ, V., La primacía de la sociedad civil, Alianza Editorial, Madrid, 1994.

ROVIRA I FORNS, J., «Contribución de las entidades no lucrativas al bienestar social» en Documentación Social ${ }^{\circ} 71$, abril-junio, 1988, pp. 175181.

RODRÍGUEZ, F., Introducción a la política social, Fundación UniversidadEmpresa/Civitas, Madrid, 1979.

RODRÍGUEZ CABRERO, G., «Entre la protección social y el bienestar social» en Varios Autores: Reflexiones sobre política económica, popular, Madrid, 1990, pp. 215-236.

SALA PRAT, G., El negocio de la pobreza o la Utopía del Bienestar, Asociación para la Promoción de la Igualdad Social, Barcelona, 1994.

SILLS, D., «Asociaciones voluntarias» en Enciclopedia internacional de las ciencias sociales, Volumen I, Agilar, Madrid, 1976, pp.

SUBIRATS, J., Análisis de políticas públicas y eficacia de la administración, Ministerio para las Administraciones Públicas, Madrid, 1989.

VARIOS AUTORES., Conceptos básicos de bienestar social. Seminario Taxonómico, Colegio Oficial de Doctores y Licenciados en Ciencias Políticas y Sociología, Madrid, 1987.

WATZLAWICK, P., El arte de amargarse la vida, Herder, Barcelona, 1988. 